\title{
Characteristics of a novel cell line ZJU-0430 established from human gallbladder carcinoma
}

\author{
Fei Zhou ${ }^{1}$, Yanhua Zhang ${ }^{2 *}$, Jihong Sun ${ }^{1 *}$ and Xiaoming Yang ${ }^{1,3^{*}}$ (B)
}

\begin{abstract}
Background: Gallbladder cancer is the most common malignant neoplasm of the biliary tract, responsible for 80-95\% of cases. Appropriate models are required for investigating the molecular pathogenesis of gallbladder cancer.

Methods: In this study, we aimed to establish a gallbladder cancer cell line from primary tumour. Single cell RNA sequencing, Light and electron microscopy, DNA content analysis, cytogenetic analysis, short tandem repeat (STR) DNA fingerprint analysis, immunophenotypic characterization, and xeno-transplantation were utilized to characterize the novel ZJU-0430 cell line in vitro and in vivo.

Results: The cell line showed multiple cell shapes and characteristic epithelial morphologies under the microscope, but no too much heterogeneity by scRNA-Seq, with a population doubling time (PDT) of $19.81 \mathrm{~h}$, which was shorter than that for GBC-SD cells. An immunophenotypic analysis revealed that ZJU-0430 cells were positive for CD24, CD44, CD29 and CD133 expression, and partially positive for CD184, and CD326 expression, and negative for CD34, CD90, CD117, and CD338 expression, similar to the primary cancer cells. A pathological analysis confirmed the origination of cell line from gallbladder tumour. ZJU-0430 cells had higher migration, invasion and proliferation properties than GBC-SD cells in vitro, and showed in vivo tumorigenicity in nude mouse xenograft settings.

Conclusions: The results confirm the potential utility of ZJU-0430 cell line as a representative model of gallbladder cancer and suggest that it could be used in the in vitro and in vivo studies of gallbladder cancer pathogenesis and to develop new therapeutics.
\end{abstract}

Keywords: Gallbladder cancer, ZJU-0430 cell line, Short tandem repeat, Epithelial, Karyotype analysis, Tumorigenicity

\section{Background}

Gallbladder carcinoma (GBC) is an invasive adenocarcinoma that originates from the epithelial linking of the digestive system [1]. GBC is a common aggressive malignant neoplasm and the fifth most deadly cancer, initiating from the gallbladder or cystic duct. Chronic cholecystitis (CC) with gallstones, dietary factors, chronic gallbladder infections, and environmental exposure to specific chemicals are considered as main risk factors for the

\footnotetext{
*Correspondence: srrhyhzhang@zju.edu.cn; sunjihong@zju.edu.cn; xmyang@zju.edu.cn; xmyang@uw.edu

${ }^{1}$ Department of Radiology, Sir Run Run Shaw Hospital, Zhejiang

University School of Medicine, Hangzhou, Zhejiang, China

${ }^{2}$ Department of Pathology, Sir Run Run Shaw Hospital, Zhejiang

University School of Medicine, Hangzhou, Zhejiang, China

Full list of author information is available at the end of the article
}

development of GBC [2], which has a wide incidence worldwide [3-5].

Despite the progress in therapeutic strategies, the overall survival rate has remained poor, mainly due to late diagnosis, early metastasis, ineffective surgical resection, and insensitivity to chemoradiation $[1,6-8]$. Therefore, it is essential to further investigate its biological behaviours, mechanisms, and potential treatments. In recent years, cancer cell lines originating from patients have proven to be a powerful tool that can be used for drug screening, drug resistance research, analysis of the tumour microenvironment, gallbladder cancer pathogenesis and the mechanism of metastasis $[9,10]$. Previously, only a few GBC cell lines derived from primary tumours have been established but insufficiently elaborated upon [11-27]. This situation necessitates the establishment of more novel GBC cell lines for studying it in detail.

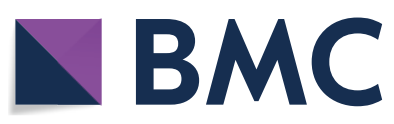

(c) The Author(s) 2019. This article is distributed under the terms of the Creative Commons Attribution 4.0 International License (http://creativecommons.org/licenses/by/4.0/), which permits unrestricted use, distribution, and reproduction in any medium, provided you give appropriate credit to the original author(s) and the source, provide a link to the Creative Commons license, and indicate if changes were made. The Creative Commons Public Domain Dedication waiver (http://creativecommons.org/ publicdomain/zero/1.0/) applies to the data made available in this article, unless otherwise stated. 
In this study, a novel gallbladder cell line derived from a primary GBC, referred to as ZJU-0430, was successfully established. All our data together confirmed that it as a potentially useful model for the further study of this disease.

\section{Methods}

\section{Patient history}

This study was performed in accordance with the Declaration of Helsinki of 1975, and the official recommendations of Chinese Community Guidelines, and was approved by the Ethics Committee and Institutional Review Board of the Sir Run Run Hospital. Written informed consent was obtained from the patient.

A 74-year-old male patient with pain in the upper abdomen was admitted in our centre. Gastroscopy showed the presence of a gastric antral ulcer (stage S2), and irregular deep concave ulcer at the gastric angle, and cancer priority. Abdominal computed tomography (CT) also found a $1.5-\mathrm{cm}$ thick wall at the bottom of the gallbladder. A radioimmunoassay showed that the patient's serum levels of a variety of biomarkers were normal (CA19-9, CA-125, AFP, CEA, and PSA) except for ferritin, which was high $(409.3 \mathrm{ng} / \mathrm{ml}, 30-400 \mathrm{ng} / \mathrm{ml})$. A radical resection of stomach and gallbladder were performed and a pathological examination showed that gastric carcinoma was a poorly differentiated adenocarcinoma derived from signet-ring cell carcinoma, whereas the primary gallbladder cancer was a well differentiated adenocarcinoma.

\section{Cell lines as control}

GBC-SD cells were obtained from the Cell Bank of Type Culture Collection of Chinese Academy of Sciences (Shanghai, China), and maintained in Roswell Park Memorial Institute (RPMI) 1640 medium (Invitrogen, Carlsbad CA, USA) supplemented by $10 \%$ fetal bovine serum (FBS) (Gibco, Grand Island, NY, USA), and 1\% penicillin/streptomycin and amphotericin B (Invitrogen).

\section{Cell culture}

The approach of primary culture was as previously described [28]. Single-cell suspensions were obtained according to the manufacturer's protocol (Miltenyi Biotec $\mathrm{GmbH}$, Germany). Specifically, the surgically resected gallbladder specimens were immediately transferred to the lab, rinsed several times in cold Dulbecco's Phosphate Buffered Saline (DPBS) containing 1\% penicillin/streptomycin and amphotericin $B$, cut into small pieces $\left(1 \mathrm{~mm}^{3}\right)$, and transferred into a gentleMACS ${ }^{\mathrm{TM}} \mathrm{C}$ tube containing the buffer from the Tumor Dissociation Kit (human), and subjected to a gentleMACS ${ }^{\mathrm{TM}}$ Tissue Dissociator. Cells were cultured in complete growth RPMI 1640 medium (containing additives) at $37{ }^{\circ} \mathrm{C}$ in a humidified incubator containing an atmosphere of $5 \% \mathrm{CO}_{2}$. Fibroblasts were removed by differential trypsinisation as described previously $[29,30]$. Serial passages were carried out every 3-4 days, routinely at a ratio of $1: 2$, and the medium was replaced when colour changed. The ZJU-0430 cell line was cultured for $>100$ passages and showed no changes in its morphology.

\section{Single cell RNA sequencing}

ZJU-0430 cells were grown in mycoplasma-free complete growth RPMI 1640 medium without antibiotics. Cells were grown to $60 \%$ confluence, and washed with $4 \mathrm{ml}$ of DPBS, and then treated with StemPro ${ }^{\mathrm{TM}}$ Accutase $^{\mathrm{TM}}$ Cell Dissociation Reagent (Invitrogen). Cells were then centrifuged at $300 \mathrm{rcf}$ for $30 \mathrm{~s}$ at room temperature and the supernatant removed without disturbing the cell pellet. Next, $0.04 \%$ bovine serum albumin fraction $\mathrm{V}$ (BSA) solution (Sigma-Aldrich, St. Louis, MO, USA) was added and then centrifugation at $300 \mathrm{rcf}$ for $5 \mathrm{~min}$. The resuspended cells were then filtered through $40 \mu \mathrm{m}$ cell strainer (Corning Incorporated, Corning, NY, USA) and following Trypan Blue staining, the cell density and viability were determined using haemocytometer.

Single-cell RNA-seq libraries were prepared with Chromium Single cell $3^{\prime}$ Reagent v2 (or v3) Kits according to the manufacturer's protocol. Single-cell suspensions were loaded on the Chromium Single Cell Controller Instrument $(10 \times$ Genomics) to generate single cell gel beads in emulsions (GEMs). In order to do this, ZJU-0430 single cells were suspended in DPBS containing 0.04\% weight/ volume BSA. About cells were added to each channel with a targeted cell recovery estimate of cells. After generation of GEMs, reverse transcription reactions were performed to generate barcoded full-length cDNA followed by the disruption of emulsions using the recovery agent and cDNA clean up with DynaBeads Myone Silane Beads (Thermo Fisher Scientific, MA, USA). The cDNA was then amplified by PCR with appropriate an appropriate number cycles which depending on the recovery cells. Subsequently, the amplified cDNA was fragmented, end-repaired, A-tailed, index adaptor ligated and library amplification. These libraries were sequenced on the Illumina sequencing platform (HiSeq X Ten) and $150 \mathrm{bp}$ paired-end reads were generated.

The Cell Ranger software pipeline (version 2.2.0) provided by $10 \times$ Genomics was used to demultiplex cellular barcodes, map reads to the genome and transcriptome using the STAR aligner, and down-sample reads as required to generate normalized aggregate data across samples, producing a matrix of gene counts versus cells. We processed the unique molecular identifier (UMI) count matrix using the $\mathrm{R}$ package Seurat (version 2.3.4). To remove low quality cells, we filtered those cells which 
with UMI larger than 8000 and gene lower than 2000 . And also we discarded low-quality cells where $>20 \%$ of the counts belonged to mitochondrial genes. After applying these QC criteria, 11,083 single cells and 20,118 genes in total remained and were included in downstream analyses. Library size normalization was performed in Seurat on the filtered matrix to obtain the normalized count. Top variable genes across single cells were identified using the method described in Macosko et al. [31]. Principal component analysis (PCA) was performed to reduce the dimensionality on the log transformed genebarcode matrices of top variable genes. Cells were clustered based on a graph-based clustering approach, and were visualized in 2-dimension using tSNE and UMAP. Likelihood ratio test that simultaneously test for changes in mean expression and in the percentage of expressed cells was used to identify significantly differentially expressed genes between clusters. Enriched biological function were analysis with DAVID website and fgsea packages in $\mathrm{R}$.

\section{Tumorigenicity}

All BALB/c nude mice experiments were carried out in accordance with Animal Research: Reporting of In Vivo Experiments (ARRIVE) guidelines, and were approved by the Zhejiang University Animal Care and Use Committee (ZUACUC) (Project License 11627). To determine the oncogenicity of the ZJU-0430 cell line, cells were subcutaneously injected into the hind flanks of four nude mice (BALB/c nu; 4-6 weeks old) (SLAC Laboratory Animals Company, Shanghai, China), Mice were maintained in laminar flow cabinets under specific pathogen-free conditions. A total of $1 \times 10^{6}$ cells were injected using a 27 -gauge needle and the tumours monitored at intervals using digital callipers. After 3 weeks, mice was killed by cervical dislocation under sodium pentobarbital $(45 \mathrm{mg} /$ $\mathrm{kg}$ ) anaesthesia. Tumours were removed, fixed in $10 \%$ formalin and subjected to pathological examination and IHC evaluation.

\section{Light and electron microscopic analysis}

Both the morphology and ultrastructure of the ZJU-0430 cells were examined following seeding into $25-\mathrm{mm}^{3}$ tissue-culture flasks. The general morphology of the cells was observed daily under a phase-contrast microscope and histopathologically compared to that of the original tumours. Electron microscopy was conducted as previously described [32] using the GBC-SD cell line as the control. Cells were harvested, pelleted, fixed $(2.5 \%$ glutaraldehyde), post-fixing ( $2 \%$ osmium tetraoxide) and then embedded in EPON resin. Ultrathin sections were stained and examined under a HT7700 microscope (Hitachi, Tokyo, Japan).

\section{In vitro growth kinetics and cell cycle analysis}

The cell growth curve analysis was obtained, as described previously [33]. The ZJU-0430 cells and GBC-SD cells were plated at 5000 cells per well, cultured at $12 \mathrm{~h}$ intervals for 3 consecutive days, and cell growth determined using an MTT assay, respectively. The growth curve was plotted, and doubling time was calculated as described (http://www.doubling-time.com/index.php).

ZJU-0430 and GBC-SD cells were plated, harvested, washed twice with cold DPBS, and fixed overnight in $70 \%$ ethanol at $4{ }^{\circ} \mathrm{C}$, treated for 30 min with RNase A $(2 \mu \mathrm{g} / \mathrm{ml})$, and then with propidium iodide (PI) at room temperature at the dark. The cell cycle distribution was determined using a FACSCanto ${ }^{\text {TM }}$ II flow cytometer (Becton-Dickinson, Mount View, VA, USA) and analysed using appropriate software.

\section{Cytogenetic analysis and STR genotyping}

Cells at the primary and 100th passage were used for analysis. Karyotyping was performed as described previously [34]. Briefly, cells were treated with $0.02 \mu \mathrm{g} / \mathrm{ml}$ Colcemid for $90 \mathrm{~min}$ at $37{ }^{\circ} \mathrm{C}$ until exponential proliferation was reached. The cell pellet was resuspended with potassium chloride $(0.075 \mathrm{~mol} / \mathrm{l})$, incubated for $20 \mathrm{~min}$ at $37{ }^{\circ} \mathrm{C}$, fixed in Carnoy's solution (methanol: acetic acid $=3: 1$ by volume), and analyzed using trypsin $\mathrm{G}$ banding.

To verify that ZJU-0430 cell line was indeed derived from humans and had no-contamination, genomic DNA from ZJU-0430 cell lines was extracted using the Gentra Puregene Cell Kit (Qiagen, Inc., Valencia, CA) according to the manufacturer's protocol. STR profiling was performed by amplifying eighteen loci simultaneously in a single tube and analyzing by capillary electrophoresis on an ABI Prism ${ }^{\circledR} 3500 \times 1$ Genetic Analyzer. Data were matched with the American Type Culture Collection (ATCC) STR database (ATCC sales order number: SO0146233).

\section{Test for mycoplasma contamination}

The cell-culture supernatant was collected and evaluated using the PCR Mycoplasma Test Kit (HuaAn Biotechnology, Hangzhou, Zhejiang, China), following the manufacturer's instructions. PCR products were separated by electrophoresis in $1 \%$ agarose and documented by photography.

\section{Immunophenotypic characterization of ZJU-0430 cells by flow cytometry}

The primary and 100-passage cells were collected for flow cytometry analysis using a FACSCanto ${ }^{\mathrm{TM}}$ II flow cytometer (Becton-Dickinson, Mount View, VA, USA), 
respectively. The panel of monoclonal antibodies used included those specific for CD24, CD44, CD29, CD34, CD90, CD117, CD133, CD184, CD326, and CD338. All antibodies and reagents were purchased from BioLegend (San Diego, CA). Data were obtained using FCS Express Software (De Novo Software, Los Angeles, CA). Antigen expression was scored as positive based on a significant shift in staining in comparison to corresponding isotype control.

\section{Wound-healing assays}

This procedure was conducted by the Cell $\mathrm{Comb}^{\mathrm{TM}}$ Scratch Assay according to the manufacturer's instructions (Merck, Darmstadt, Germany). Briefly, a wound was created in the cell monolayer using cell comb, when the cells reached semi-confluence, and they were cultured thereafter for an additional $72 \mathrm{~h}$ at $37{ }^{\circ} \mathrm{C}$ and $5 \%$ $\mathrm{CO}_{2}$. Eight scratched fields were randomly chosen for cell counting.

\section{Migration and invasion assays}

The in vitro migration and invasion assays were performed as previously described [35, 36]. Briefly, $1 \times 10^{4}$ cells were seeded into cell-culture insert wells (Corning Incorporated, Corning, NY, USA) with or without Matrigel-coating (BD Biosciences, Bedford, MA, USA) in RPMI 1640 medium. The extent of migration and invasion was determined after cultured for $48 \mathrm{~h}$. The cells on the lower surface were fixed and stained with Giemsa solution.

\section{Colony formation}

A colony formation assay was used to assess the proliferative ability of the ZJU-0430 cells. A single-cell suspension was prepared and plated on 6-well plates (200 cells/ well) in triplicate and cultured for 14 days. The colonies were stained with $1 \%$ crystal violet for $30 \mathrm{~s}$ after fixation with $4 \%$ paraformaldehyde for 5 min.

\section{Immunostaining}

Tissue section slides from original patient (GBC and gastric cancer), ZJU-0430 tumours grown in mice, and cytospins of ZJU-0430 cells were used in this experiment as described previously [37, 38]. For cytospins, ZJU-0430 cells were plated onto glass coverslips, fixed with $4 \%$ paraformaldehyde (PFA), blocked with 10\% goat serum, incubated with primary antibodies (vimentin, CK-pan, CK7, and CK19 all from cell signaling technology (CST)) at $4{ }^{\circ} \mathrm{C}$ overnight, followed by the addition of immunofluorescent labelled antibodies [FITC/PE goat anti-rabbit IgG $(\mathrm{H}+\mathrm{L})]$. For tissue slides, $5 \mu \mathrm{m}$ sections were fixed onto the slides, dewaxed, rehydrated, heated for antigen retrieval, incubated in $3 \%$ hydrogen peroxide to inactivate endogenous peroxidase, blocked with 5\% BSA, and then incubated with primary antibodies specific for the following proteins, MUC1, MUC2, MUC4, MUC5AC, MUC6, AFP, Hepatocyte, Glypican-3, GS, CK20, CAD17, CDX2, beta-catenin, STAB 2, vimentin, MMP-2, MMP-9, CK7, and CK19. A 3,3' diaminobenzidine tetrahydrochloride (DAB) horseradish peroxidase colour development kit (Boster) was used for visualizing target protein and Mayer's haematoxylin (Boster) was used for counterstaining.

\section{Results}

Histopathologic establishment of a new GBC cell line, ZJU-0430

A routine pathological examination of the original tumour was performed and compared to the similar observations made in the established cell lines. Haematoxylin and eosin (H\&E) staining of the primary GBC from the patient's surgical specimen showed well-differentiated adenocarcinoma polygonal cells that formed ribbons, nests, and sheets (Fig. 1a), characteristic of a classical GBC morphology. The gastric cancer showed a poorly differentiated adenocarcinoma derived from signet-ring cell carcinoma with clusters, beams, or scattered infiltration, with few cytoplasm, nuclear deviation, with obvious atypia and mitosis. The proliferation of interstitial fibrous tissue and capillaries is obvious (Fig. 1b). The established cell lines grew in adherent monolayer pattern with multiple forms; there was no change in the morphology during passage (Fig. 1c). Under the electron microscope, ZJU-0430 cells showed typical epithelial properties, including the presence of numerous organelles (ribosomes, rough endoplasmic reticula, mitochondria), large irregular nuclei with deep sunken caryotheca, microvillus-like projections on the cell surface, and numerous desmosomes forming intercellular connections. In contrast to ZJU-0430 cells, the GBC-SD cells had fewer microvillus-like projections on the cell surface, had sunken caryotheca, and had desmosomes that formed intercellular connections (Fig. 1d).

\section{H\&E staining analysis and epithelial characteristics of ZJU-0430 cell line}

As showed in Fig. 2a, the ZJU-0430 cell line had a moderately abundant strongly basophilic cytoplasm. The nuclei were ovoid with coarse chromatin and occasional irregular contours. The ZJU-0430 cell line and the original tumour were staining for CK-pan, vimentin, CK7, and CK19. The data showed that there was CK-pan positive staining in both the ZJU-0430 cell line and in the tumour cells in the original tissue. The ZJU-0430 cell line was negative for vimentin expression whereas the mesenchymal cells were positive for vimentin expression (Fig. 2b, c). Both the ZJU-0430 cell line, as well tumour cells in the 
a

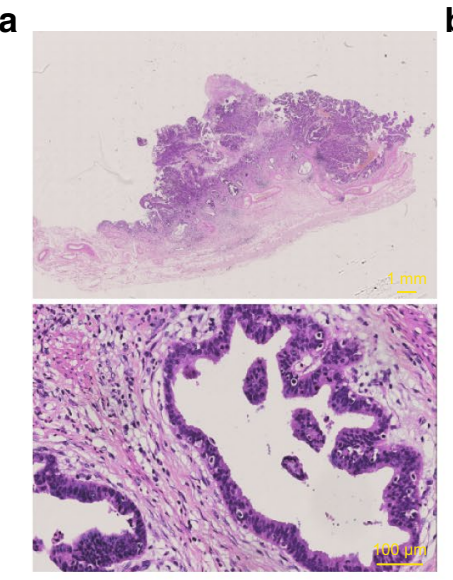

b

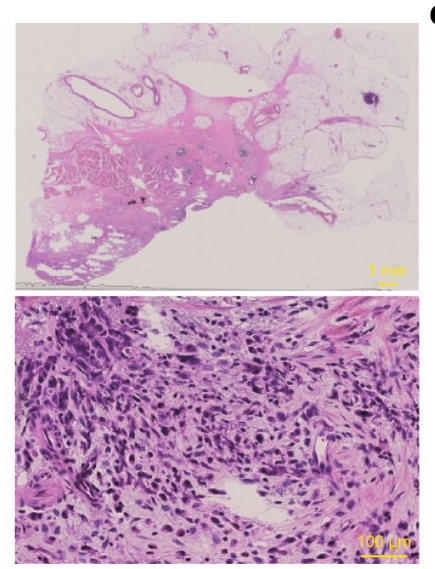

C

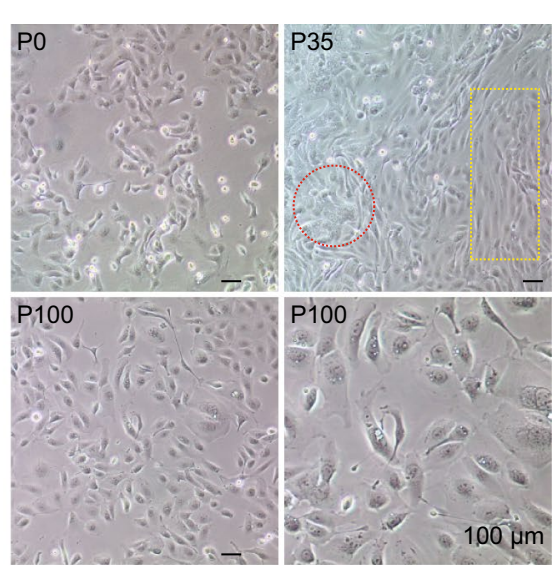

d

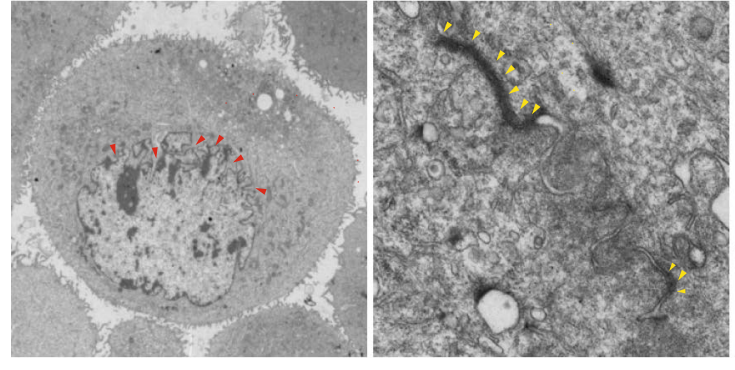

ZJU-0430

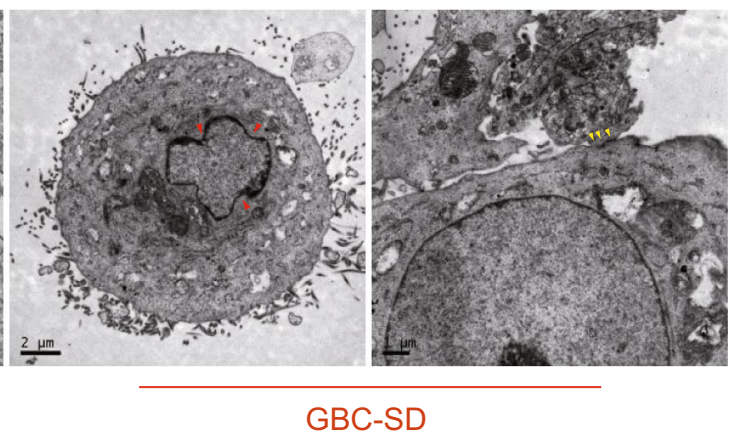

Fig. 1 Histopathological image of original specimen and morphological characteristics of ZJU-0430 cell line. a H\&E staining analysis of tissue from patient with GBC and from that with well-differentiated adenocarcinoma. $\mathbf{b}$ H\&E staining analysis patient's gastric cancer and from that poorly differentiated adenocarcinoma from signet-ring cell carcinoma. c Morphology of ZJU-0430 cell lines under a phase contrast microscope at different passages. d Ultrastructure features of ZJU-0430 and GBC-SD with abundants of organelle (ribosomes, rough endoplasmic reticula, mitochondria), large irregular nuclei with deep sunken (indicated by red arrow), microvillus-like projections on the cell surface (indicated by yellow arrow), and numerous desmosomes in the intercellular connections

original tissue, were positive for CK7 and CK19 (Fig. 2d, e). These results confirmed that the ZJU-0430 cell lines were originated from gallbladder epithelium.

\section{Mycoplasma contamination}

Uphoff and Drexler reported that $1-35 \%$ cells are prone to mycoplasma contamination in primary early passages and in continuous cell culture [39]. In order to assess if the ZJU-0430 cell line suffered from mycoplasma, mycoplasma contamination was assessed using a PCR assay. As shown in Fig. 3, no bands were detected in samples from the ZJU-0430 cell line, indicating that it is free of mycoplasma contamination.

\section{DNA profiles}

STR profiles were prepared to confirmed the species of origin of the JU-0430 cell line. Analysis of the ZJU-0430 cell line STR profiles compare to the ATCC and DSMZ databases revealed it to be of human origin. The data also excluded the possibility of cross-contamination with other cell lines, including the HeLa cell line (Table 1, Additional files 1, 2).

\section{Growth characterization in vitro}

The ZJU-0430 cell line was characterized for its ability to proliferate and progress through the cell cycle, the GBCSD cell lines was used as a control (Fig. 4a). The PDT of the ZJU-0430 cells and the GBC-SD cells were approximately $19.81 \mathrm{~h}$ and $33.5 \mathrm{~h}$, respectively. The ZJU-0430 cell line grew shorter than the GBC-SD cell line on the condition of initial cell concentration.

The DNA contents of the ZJU-0430 cell line and GBCSD cell lines were analysed by flow cytometry. ZJU-0430 cells had higher PI $\left({ }^{* *} \mathrm{P}<0.05\right)$ and SPF $\left({ }^{* *} \mathrm{P}<0.05\right)$ than GBC-SD cells (Fig. 4b), and therefore have a higher proliferative potential compared with the GBC-SD cells.

\section{Cytogenetic analysis}

Chromosomal abnormalities such as number and structure abnormalities are frequently found as cancer 

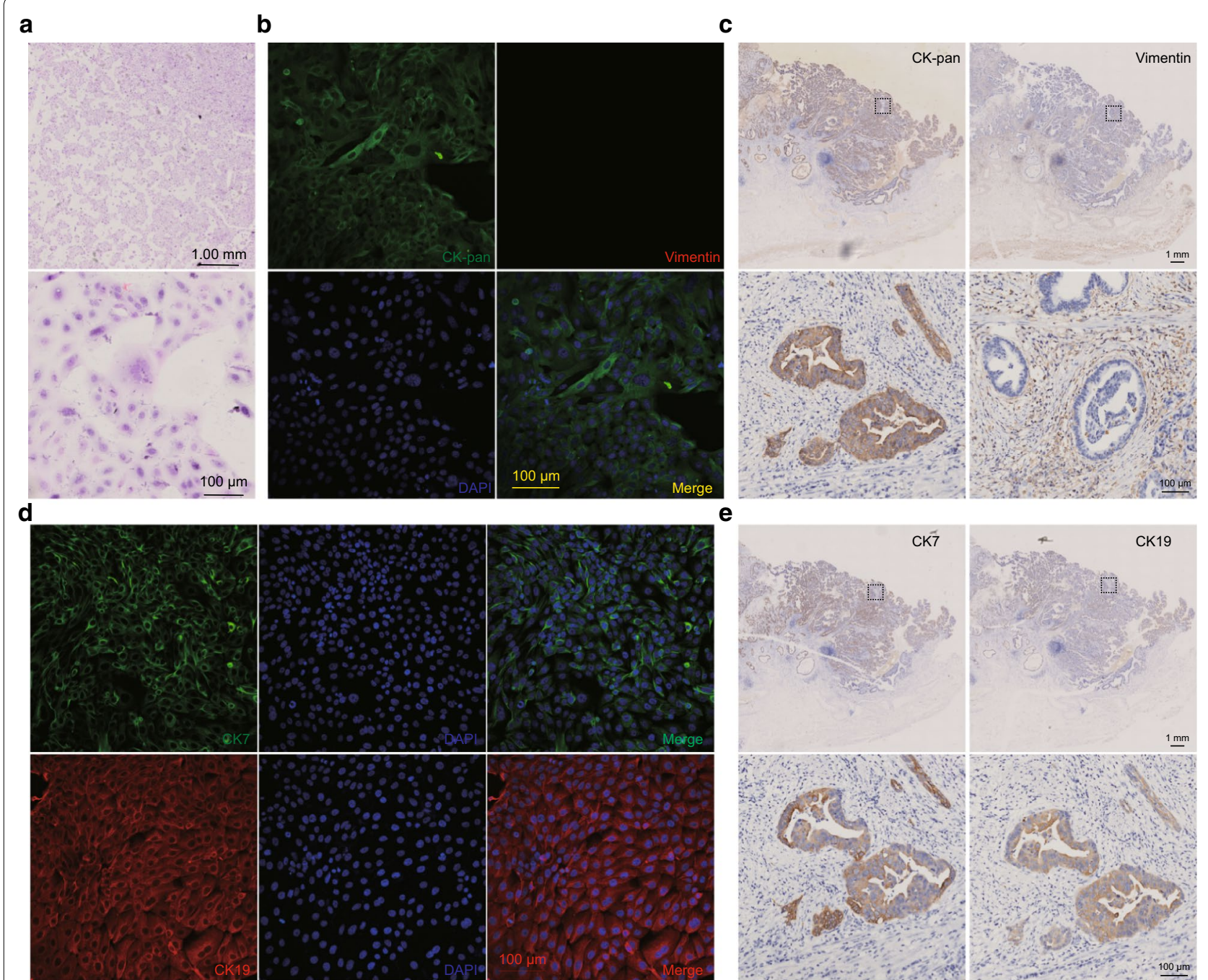

Fig. 2 Immunostaining on slides of ZJU-0430 cells and original tumours. a H\&E staining analysis of ZJU-0430 cells, showed moderately abundant strongly basophilic cytoplasm, ovoid nuclei with coarse chromatin and occasional irregular contours. b, c CK-pan are strongly positive in both cells and tissue sections, and vimentin is polarity. $\mathbf{d}, \mathbf{e}$ CK7 and CK19 are all expressed positively on cells and tissue sections

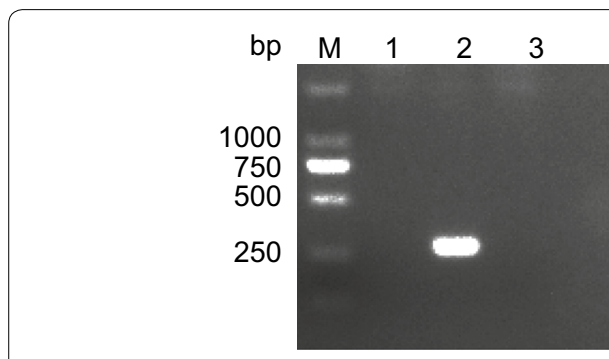

Fig. 3 Mycoplasma examination Agarose gel electrophoresis analysis showed that the PCR products of ZJU-0430 had no relevant band (3); (1) and (2) are negative and positive controls, respectively progresses. A cytogenetic analysis of the ZJU-0430 cell line at the primary stage and P100 were performed using banding technology. The results showed both numerical and structural aberrations at different passages. A complex near-triploid clone with a modal number of chromosomes of 73 showed a representative karyotype categorized as: $70-74, \mathrm{XX},-\mathrm{X},+4,-5$, der (6) t (6: ?) (P22; ?), +7, $-10,+14,-15,+17$, der (17) t $(5 ; 17)($ p13: p11.2) $\times 2,-18,-19,+20,+$ I (21) (q10), $+22 \times 2,+\operatorname{mar} 1,+\operatorname{mar} 2$ [CP15] (Fig. 4c, e) at P100. The karyotype of primary cells was also investigated, and the results were $69-76, \mathrm{XX},+1,+2 \times 2$, $-5,+3 \times 2,+4 \times 2,+\operatorname{der}(5) \mathrm{t}(5 ; 17)(\mathrm{q} 13 ; \mathrm{q} 11.2$ ? $) \times 2$, $\operatorname{der}(6) \mathrm{t}(6 ;$ ?) (p23; ?), +7, +8 $\times 2,+9 \times 2,+10,+11$, $+12 \times 2,+13,+14 \times 2,-16,+18,+20,+21 \times 2$, 
Table 1 STR profile report of ZJU-0430 cell line

\begin{tabular}{lll}
\hline Sample of ZJU-0430 cells & & \\
\hline STR loci & Allele 1 & Allele 2 \\
\hline D3S1358 & 17 & \\
TH01 & 7 & 10 \\
D21S11 & 30 & 31 \\
D18S51 & 14 & 21 \\
Penta_E & 12 & \\
D5S818 & 11 & 12 \\
D13S317 & 8 & 12 \\
D7S820 & 11 & 13 \\
D16S539 & 11 & 12 \\
CSF1PO & 11 & Y \\
Penta_D & 11 & 17 \\
Amelogenin & $X$ & 12 \\
vWA & 16 & \\
D8S1179 & 10 & 15.2 \\
TPOX & 11 & 24 \\
FGA & 23 & \\
D19S433 & 14 & \\
D2S1338 & 17 & \\
\hline & & \\
\hline
\end{tabular}

$+22 \times 2, \operatorname{mar} 1 \times 2, \operatorname{mar} 2 \times 2$, [CP5] (Fig. 4c, e). The symbol "?" represent chromosome classification and condition are unknown. These results revealed that ZJU-0430 chromosomal abnormalities included gains, losses, translocations and other events.

\section{Immunophenotypic characterization}

In order to investigate the stemness of the ZJU-0430 cells, an immunophenotypic analysis of the ZJU-0430 cells was performed by flow cytometry. The immunophenotypes of the primary and 100th passage cells were almost identical. The ZJU-0430 cells were positive with CD24, CD44, CD29, and CD133, partially positive for CD184, and CD326; and negative for CD34, CD90, CD117, and CD338 (Table 2, and Additional file 3: Figure $\mathrm{S} 1$ ). The result show that the ZJU-0430 cells have partial stemness.

\section{Migration and invasion of ZJU-0430}

In order to investigate the ability of the ZJU-0430 cells to migrate, invade, and proliferate, wound-healing and Transwell (with or without Matrigel) assays were performed. As shown in Fig. 5a, although the scratch wound on ZJU-0430 cells was almost closed after $18 \mathrm{~h}$ culture, the scratch wound distance of the GBC-SD cells did not change after $72 \mathrm{~h}$ culture. As shown in Fig. 5b, the number of ZJU-0430 cells that invaded the basement membrane (with or without Matrigel) was significantly higher than that of GBC-SD cells.

\section{Colony formation}

A colony formation was also performed to examine the ability of ZJU-0430 cells proliferate. As shown in Fig. 5c, ZJU-0430 cells form more compromised tumours than GBC-SD cells.

\section{Nude mice studies}

In order to investigate their in vivo tumorigenic capacity, ZJU-0430 cell suspensions were injected subcutaneously into the flank of nude mice. Tumour development was observed in all of mice and no obvious metastatic lesions were observed. Gross examination revealed that the tumours were round or oval shaped, and often showed mucus production. The atypia of tumour cells was obvious, when arranged with a small strip of cord and viewed under a microscopy they formed different cavities that included foam cells, cancer cells and normal epithelial cells (Fig. 5d, e).

\section{Immunohistochemistry}

To characterize the original ZJU-0430 cell lines, the original GBC, and the original gastric cancer, a series of markers were examined by IHC technology. As shown in Fig. 6a, ZJU-0430 xenografts of nude mice were positive for the expression of CK-pan, CK7, CK19, MUC5AC, MUC6, and MMP-2, and weakly expressed GS and CK20, there was no expression of AFP, Hepatocyte, Glypican-3, CAD17, CDX2, $\beta$-catenin, SATB2, MUC2, vimentin, and MMP-9. In addition, the original GBC tumour showed negatively staining CDX2 (Fig. 6b), and the original gastric cancer showed positive staining for CK20, CAD17, CDX2, and was negative for $\beta$-catenin and SATB2. These results confirm the ZJU-0430 cells originate from the original GBC (Additional file 4: Figure S2).

\section{Heterogeneity analysis by scRNA-Seq}

To interpret the characteristic observed during the experimental investigation, we do single cell RNA sequencing analysis on ZJU-0430 cell line. By using Seurat pipeline, we identified 3 main cell clusters (Fig. 7a, Additional file 5: Figure S3a, b). And cell cycle effects did not contribute for the main heterogeneity as cells in different mitotic cycle presented in all 3 clusters (Fig. 7b). All those cell cluster were CD24, CD44, CD29 and CD133 positive and with partial of the cells in the C3 cluster were CD326 negative (Additional file 5: Figure S3c). To expound the characteristic of each cell cluster, we did DEG analysis between each group and using the DEGs for DAVID enrichment analysis. C1 cluster highly expressed genes 

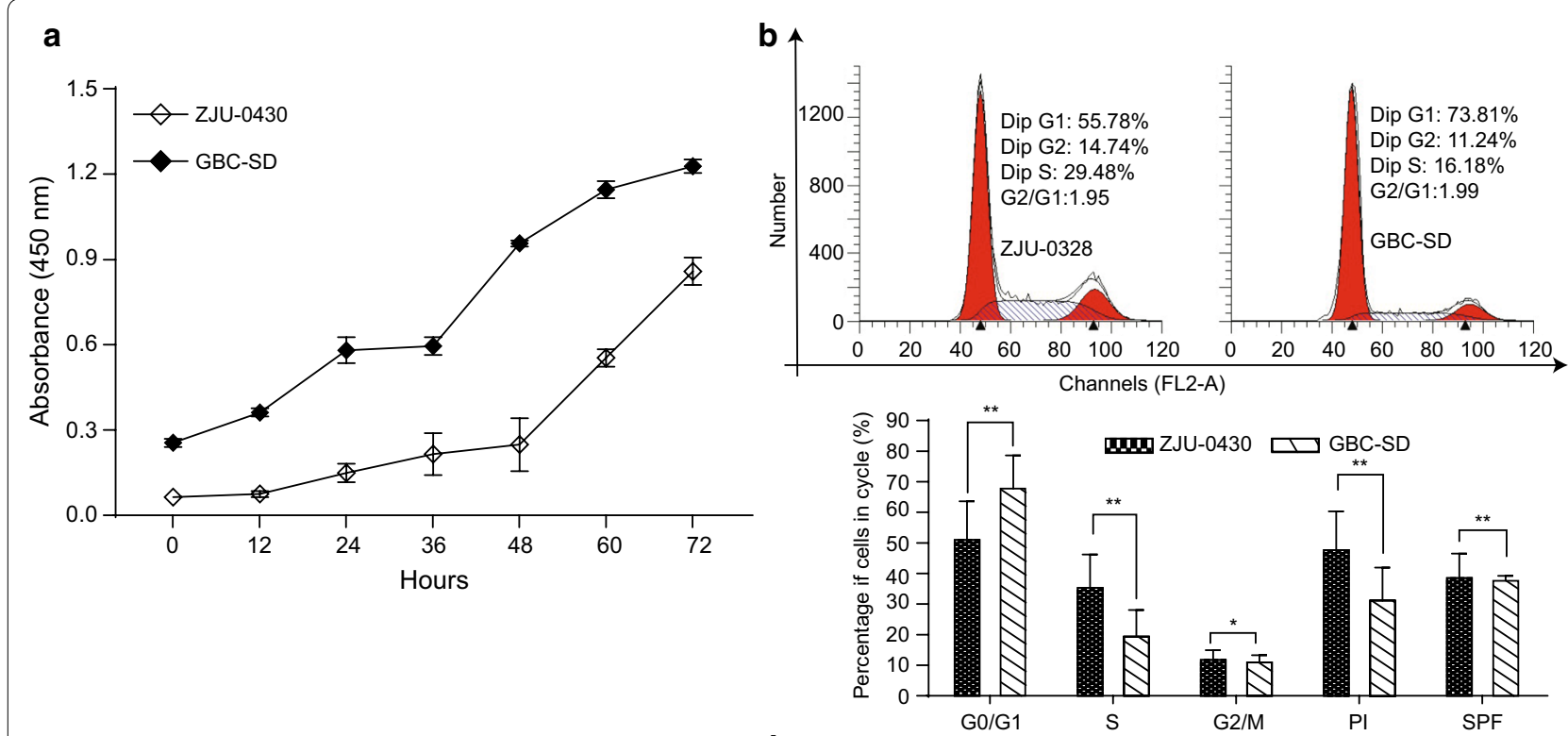

C

d
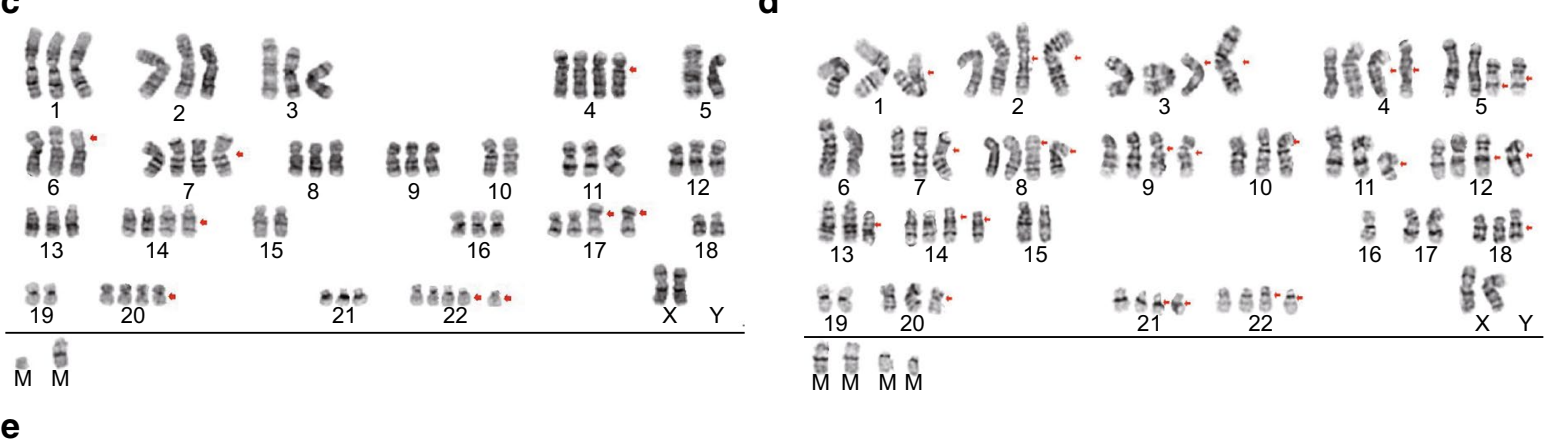

Mิ $\mathrm{M}$ M $\mathrm{M}$

Karyotype

ZJU-0328 cell line

\begin{tabular}{l:l} 
Primary & $P 100$ \\
\hline $69-76, \mathrm{XX},+1,+2 \times 2,-5,+3 \times 2,+4 \times 2,+\operatorname{der}(5) \mathrm{t}(5 ;$ & $70-74, \mathrm{XX},+\mathrm{X},+4,-5, \operatorname{der}(6) \mathrm{t}(6 ; ?)(\mathrm{P} 22 ; ?),+7,-10,+14$, \\
$17)(\mathrm{q} 13 ; \mathrm{q} 11.2 ?) \times 2, \operatorname{der}(6) \mathrm{t}(6 ; ?)(\mathrm{p} 23 ; ?),+7,+8 \times$ & $-15,+17, \operatorname{der}(17) \mathrm{t}(5 ; 17)(\mathrm{p} 13 ; \mathrm{p} 11.2) \times 2,-18,-19,+20$, \\
$2,+9 \times 2,+10,+11,+12 \times 2,+13,+14 \times 2,-16,+18,+$ & $+\mathrm{i}(21)(\mathrm{q} 10),+22,+22,+$ mar $1,+\operatorname{mar} 2$ [CP15] \\
$20,+21 \times 2,+22 \times 2, \operatorname{mar} 1 \times 2, \operatorname{mar} 2 \times 2,[\mathrm{CP} 5]$ &
\end{tabular}

Fig. 4 Double time, DNA content, and cytogenetic assay. a The PDT of ZJU-0430 cells and GBC-SD were $20 \mathrm{~h}$ and $33.5 \mathrm{~h}$, respectively. And the growth curves are shown. b Representative cell cycle distribution of ZJU-0430 cells, $55.78 \%$ in G1 phase, $14.74 \%$ in G2 phase, and $29.48 \%$ in S phase, and GBC-SD cells, $73.81 \%$ in G1 phase, $11.24 \%$ in G2 phase, and 16.18\% in S phase, and statistical analysis. c-e Representative G-banding profile of ZJU-0430 and GBC-SD (abnormal chromosome indicated by red box)

associated with regulation of Wnt signaling pathway (Fig. 7c, Additional file 5: Figure S3d) and cellular component of extracellular exosome (Additional file 5: Figure S3e). C2 cluster enriched genes involved with apoptotic process (Fig. 7d, Additional file 5: Figure S3f). And C3 cluster expressed less genes and transcripts, which might due to nuclear-transcribed mRNA catabolic process associated with nonsense-mediated decay (Fig. 7e,
Additional file 5: Figure S3g). These results indicated that the ZJU-0430 mainly constituted by cells with stemness signature and no too much heterogeneity.

\section{Discussions}

Human GBC is an extremely malignant disease owning to its relative rarity, histological heterogeneity, and proximity to vital structures. Surgical resection, and 
Table 2 Immunophenotype profile of primary ZJU-0430 cells as determined by flow cytometry

\begin{tabular}{lll}
\hline Phenotype & Primary cells & P100 cells \\
\hline CD 24 & + & + \\
CD 44 & + & + \\
CD 29 & + & + \\
CD 34 & - & - \\
CD 90 & - & - \\
CD 117 & - & - \\
CD 133 & + & + \\
CD 184 & \pm & \pm \\
CD 326 & \pm & \pm \\
CD 338 & - & - \\
\hline
\end{tabular}

- Negative staining, + positive staining, $\pm \mathrm{dim} /$ partial staining ideal experiment model to investigate the biological behavior of GBC cells and may aid in the development of novel adjuvant therapies, potential anticancer agents, or new diagnostic strategies.

Cell lines derived from primary tumours are more likely to reflect the characteristics of the original primary tumour more accurately. Based on this idea, here we report the establishment of a GBC cell line designated as ZJU-0430, which was derived from a 74-year-old male patient who had some serum ferritin abnormalities, and GBC that was a well-differentiated adenocarcinoma. The cell grew in adherent monolayer pattern with at least two morphologies that co-existing. scRNA-Seq results revealed that ZJU-0430 cell line was no too much heterogeneity although the morphological difference. Optical microscopy, ultrastructural examination, immunostain-

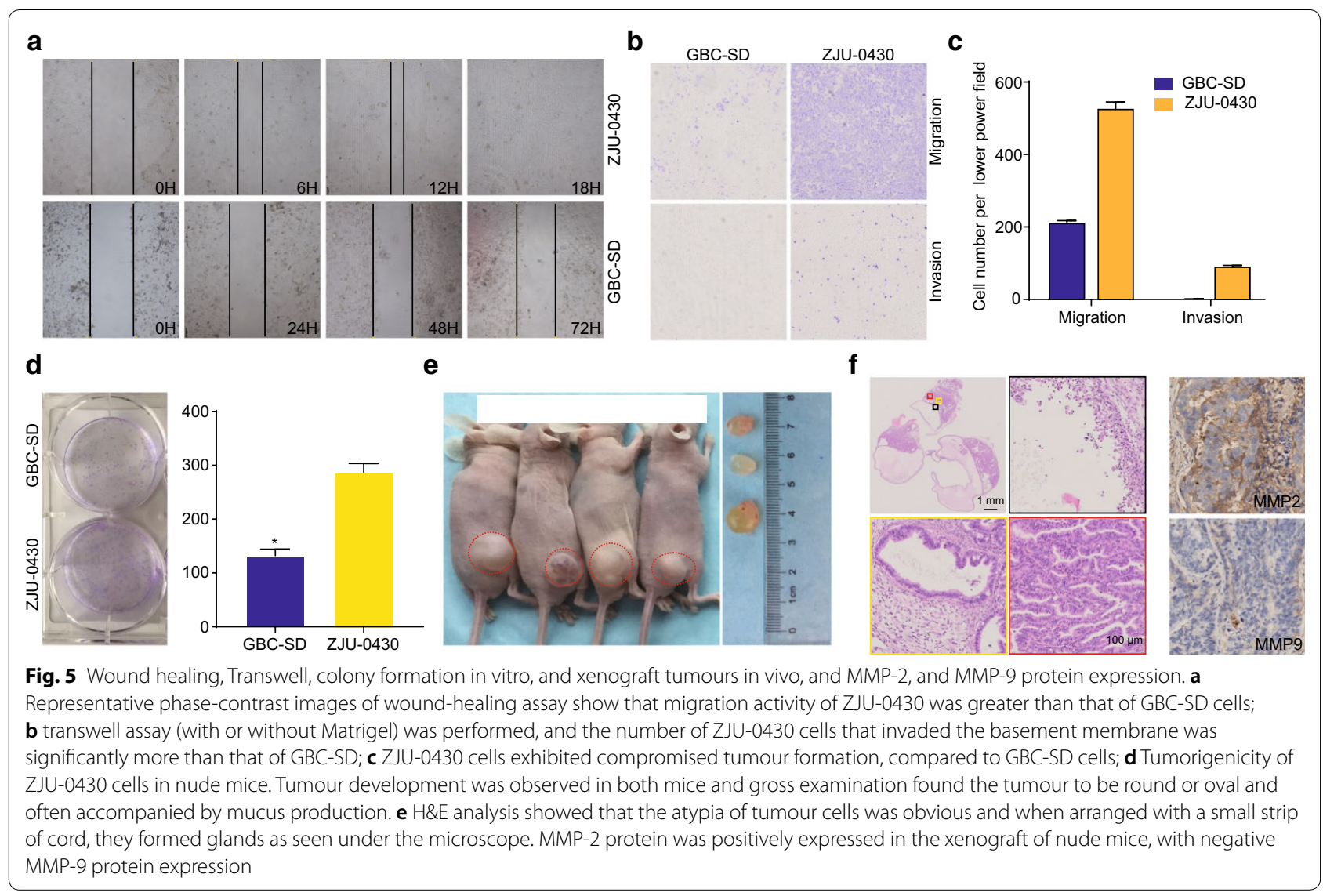

chemoradiotherapy are ineffective $[1,8,40]$, and the median survival is less than 10 months [41] while the 5 -year survival rate is less than 5\% [42]. In recent years, a series of human carcinoma GBC cell lines have been established from peritoneum effusion, surgical and autopsy tissues, biopsy specimens, and metastatic lesions $[19,26,27,37,43,44]$. Novel GBC cell lines provide an ing of epithelial markers for positive (CK-pan, CK7, and CK19) and negative mesenchymal expression (vimentin), and $H \& E$ staining of cells displayed features that were typical of malignant epithelial cells. The STR genotyping analysis showed the ZJU-0430 cell line was of human origin and that it differed from other established cell lines. A mycoplasma examination confirmed ZJU-0430 to be 


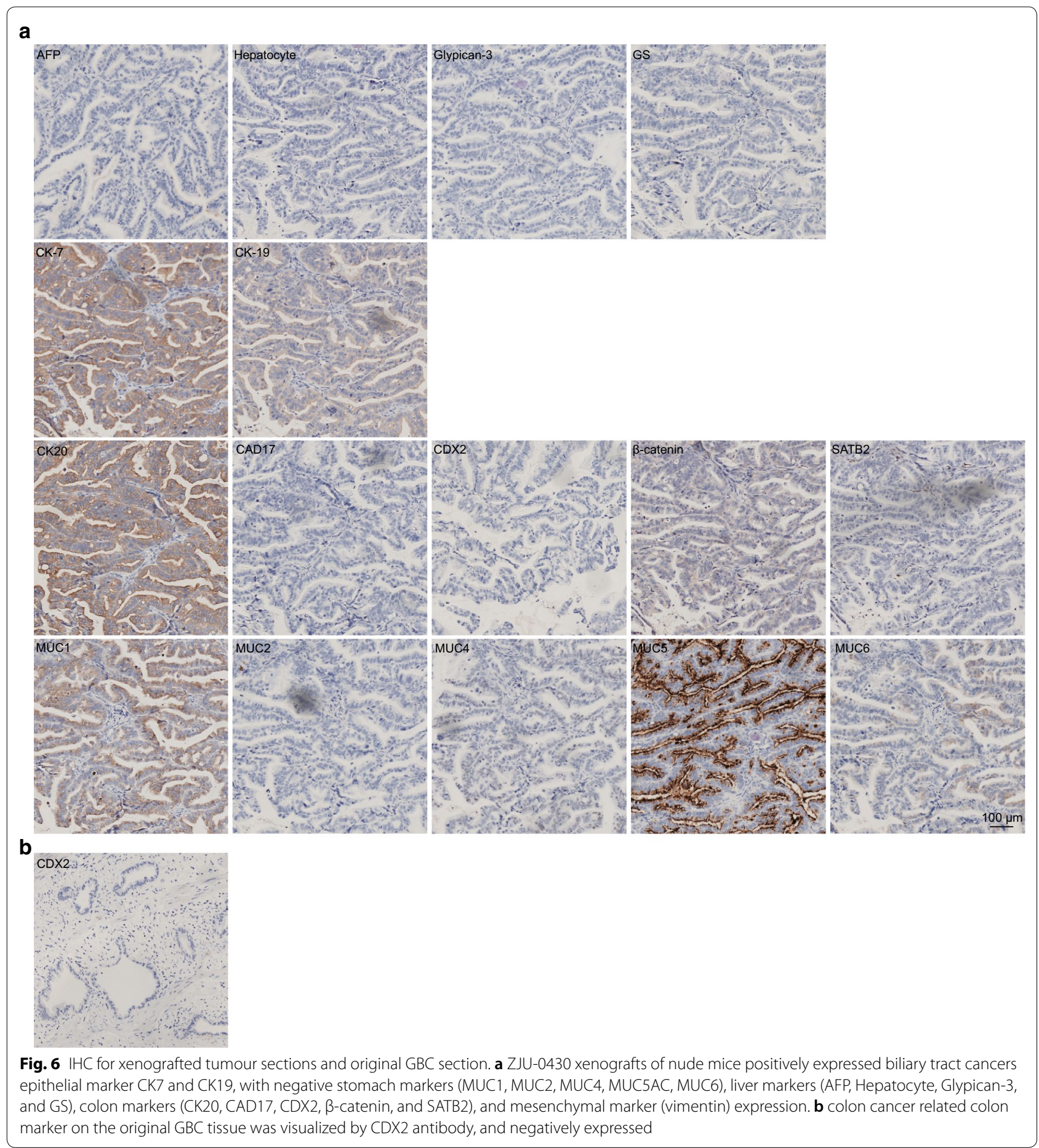

free of mycoplasma. The PDT was approximately $19.81 \mathrm{~h}$, which was shorter than GBC-SD cells. Taken together, these results suggest that ZJU-0430 cell line is a representative of the disease and may be used for pre-clinical investigation of the pathogenesis and treatment of GBC.
Recently, Devendra Chaudhary, et al. reported that $46.7 \%$ of GBCs have an abnormal karyotype [45]. In the present study, the karyotypes of ZJU-0430 cell line were found to be near-triploid both at primary and at P100, with the structural aberrations including gains, losses, and additional material of unknown origin on 


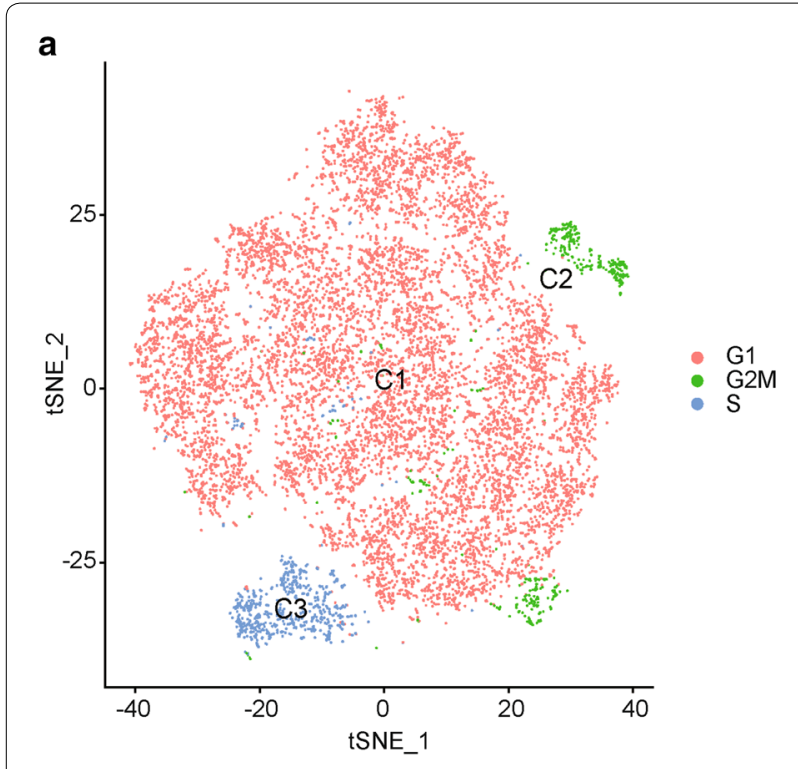

C

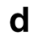

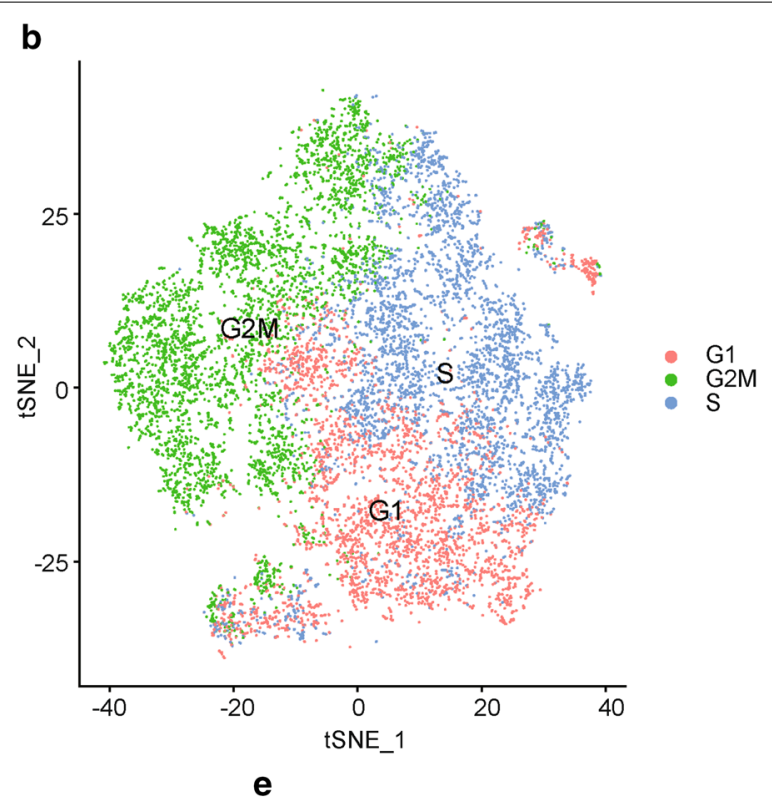

e

GO_WNT_SIGNALING_PATHWAY

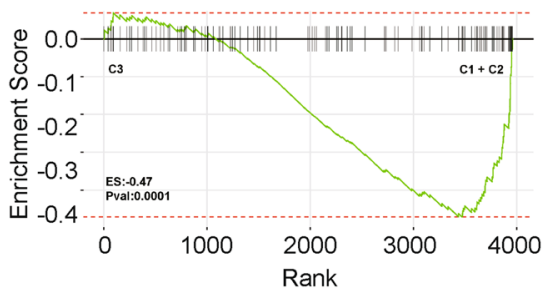

GO APOPTOTIC SIGNALING PATHWAY

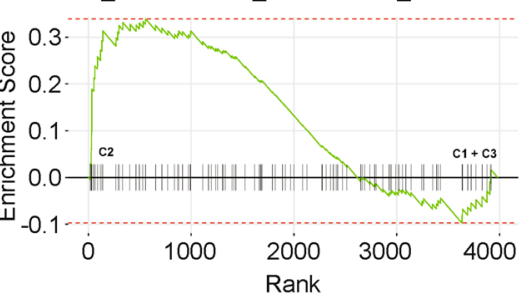

GO_NUCLEAR_TRANSCRIBED_MRNA_CATAB OLIC_PROCESS_NONSENSE_MEDIATED

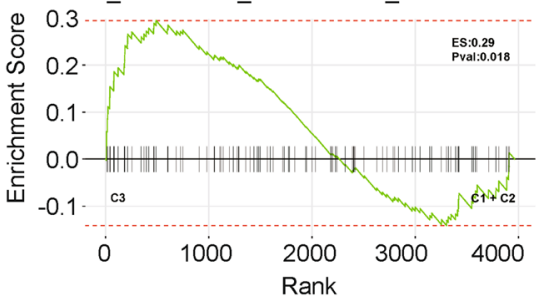

Fig. 7 The heterogeneity of ZJU-0430 cell line by RNA-Seq. a tSNE plot of ZJU-0430 cell line clusters defined by Seurat pipline. b tSNE plot of cell cycle assignment of each cell cluster. c GSEA plot depicting the enrichment of genes upregulated in Wnt signaling pathway in C1 and C2 cluster. $\mathbf{d}$ GSEA plot depicting the enrichment of genes upregulated in apoptotic signaling pathway in C2 cluster. e GSEA plot depicting the enrichment of genes upregulated in nuclear transcribed mRNA catabolic process nonsense mediated in C3 cluster

chromosomes 6 and 17 (one derivative chromosome 6 and two derivative chromosome 17) resulting from an unbalanced translocation with others chromosomes (chromosome 6 to an unknown chromosome, and chromosome 17 to the short arm of chromosome 5). An isochromosome was found for the short arm of chromosome 21; and two unknown marker chromosomes were also detected. None of these structural aberrations matched those in the previous cytogenetic studies of GBC [26, 37]. Cytogenetic abnormalities with mutations are usually related to oncogenic activation; therefore, further analysis may yield potential molecular targets in the context of this disease.

Mycoplasma can impede a whole range of cellular properties and functions and hinders the use of cells and their derived products in pharmacological area [46]. The culture supernatant derived from the ZJU-0430 cells was subjected to PCR analysis, and was found to be mycoplasma free. We have therefore identified the ZJU0430 cell line as a useful tool to study GBC.

Although numerous GBC cell lines have been documented, including G-415, NOZ, KMG-A, GBK-1, FUGBC-1, FU-GBC-2, PTHrP-GBK, GB-d1, TGBC1TKB, TGBC2TKB, OCUG-1, TUGBK-1, HAG-1, GBC-SD, SGC-996, EH-GB1, EH-GB2 and TJ-GBC2 [11-20, 22, $23,25,27,37,47,48]$, the surface markers present in GBC have yet to characterized. Meanwhile, cancer stem cells have highly clinically relevant in the development, progression, aggressiveness, recurrence, and metastasis of tumours. Our study is the first to characterize progenitor cells in a newly established GBC cell line. Our results are consistent with other reports [49-51] and since we found these cells to be positive for CD24, CD44, CD29, and CD133, partially positive for CD184, and CD326, and negative for CD34, CD90, CD117, and CD338. Taken together, these data showed that ZJU-0430 cell had stemness properties. 
GBC is highly aggressive in patients [52]; therefore, the malignant phenotype of ZJU-0430 cell line was explored both in vitro and in vivo. Our data showed that the migration, invasion, and proliferation abilities of ZJU0430 are much greater than of GBC-SD cells, and in addition there were higher levels of expression of metastatic-related marker MMP-2. The cells were capable of forming solid tumours that were histologically identical to the original surgical specimen, indicating that the GBC cell line could be used as a reliable model for in vivo preclinical research.

An immunoblotting assay showed ZJU-0430 cells to be positive for biliary tract cancer epithelial marker (CKpan, CK7, and CK19), which are found to be positive at high rates in real GBC specimens. The mesenchymal marker vimentin was also tested, but it is not found to be expressed. Since the patient (source of ZJU-0430) had been diagnosed with gastric carcinoma before GBC, gastric carcinoma markers were also explored on the xenograft tumour. The gastric carcinoma markers MUC2, MUC5AC, and MUC6 were expressed weakly or not at all. Since the colon and liver are contiguous with each other, the origin of ZJU-0430 cell was a little unclear. In this study, liver markers (AFP, Hepatocyte, Glypican-3, and GS) and colon markers (CK20, CAD17, CDX2, $\beta$-catenin, and SATB2) were used for staining of xenograft-derived tumours, with the result that all markers were either expressed only weakly, or were not express at all. In addition, the colon cancer marker CDX2 protein were also not found to be expressed on original GBC. Therefore, ZJU-0430 cell line was verified to be originated from the gallbladder primary site.

\section{Conclusion}

We have successfully established a human GBC cell line referred to as ZJU-0430 that is identical to the original surgical specimen. This well-characterized GBC cell line should be helpful in the investigation of the pathogenesis of GBC, and may help in developing early diagnostic tools as well as potential targeted therapies.

\section{Additional files}

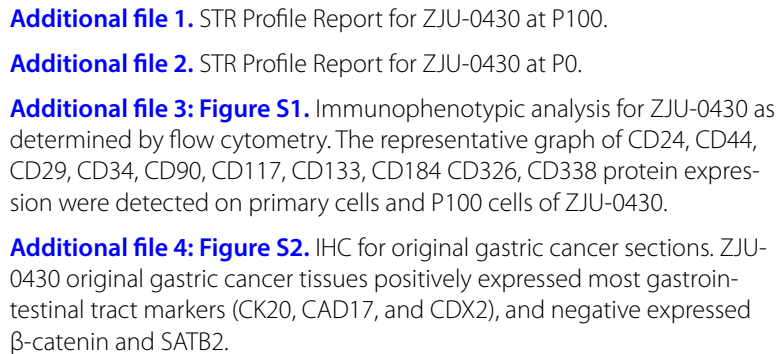

Additional file 4: Figure S2. IHC for original gastric cancer sections. ZJU0430 original gastric cancer tissues positively expressed most gastrointestinal tract markers (CK20, CAD17, and CDX2), and negative expressed $\beta$-catenin and SATB2.

Additional file 5: Figure S3. Characteristic of ZJU-0430 cell line in by scRNA-Seq data. (a) tSNE plot of ZJU-0430 cell line clusters defined by Seurat pipline before merging similar sub cell clusters. (b) UMAP plot of ZJU-0430 cell line clusters as showed in (a). (c) Dot heatmap of CD24, CD44, CD29, CD133 expression in each cell clusters. Heatmap showed the expression pattern of genes associated with Wnt signaling pathway (d), extracellular exosome (e), apoptotic signaling pathway (f) and nuclear transcribed mRNA catabolic process nonsense mediated (g).

\section{Abbreviations}

STR: short tandem repeat; PDT: population doubling time; GBC: gallbladder carcinoma; CC: chronic cholecystitis; CT: computed tomography; RPMl: Roswell Park Memorial Institute; FBS: fetal bovine serum; DPBS: Dulbecco's Phosphate Buffered Saline; BSA: bovine serum albumin fraction V; GEMs: gel beads in emulsions; UMI: unique molecular identifier; PCA: principal component analysis; ZUACUC: Zhejiang University Animal Care and Use Committee; PI: propidium, iodide; ATCC: American Type Culture Collection; H\&E: haematoxylin and eosin; CST: cell signaling technology; DAB: 3,3' diaminobenzidine tetrahydrochloride.

\section{Acknowledgements}

The authors thank Qing Ruan and Tao Zhu for excellent technical support.

\section{Authors' contributions}

FZ performed experiments and analysis and prepared the manuscript. YHZ, JHS and XMY conceived and designed the experiments. All authors read and approved the final manuscript.

\section{Funding}

This work was supported by the Key Program of National Natural Science Foundation of China (no. 81430040 to X.Y.); National Natural Science Foundation of China (no. 81571738, 81871403 to J.S.); National Key Research and Development Program of China (no. 2016YFA0100900 to J.S.); Key Research and Development Program of Zhejiang Province (no. 2019 C03014 to J.S.); Medical and Health Program of Zhejiang Province (no. 2019338991 to F.Z.). The funders had no role in study design, data collection, analysis, and interpretation; preparation of the manuscript; and decision to submit the manuscript for publication.

\section{Availability of data and materials}

All data during this research are included in this published article.

\section{Ethics approval and consent to participate}

Tumour specimens were obtained with the approval of the ethics committee of Sir Run Run Hospital, Zhejiang University, Zhejiang, China. Written, informed consent was obtained from each patient. Animal care and experimental protocols were approved by our Institutional Animal Care and Use Committee. All surgeries were performed under sodium pentobarbital anesthesia.

\section{Consent for publication \\ Not applicable.}

\section{Competing interests}

The authors declare that they have no competing interests.

\section{Author details}

${ }^{1}$ Department of Radiology, Sir Run Run Shaw Hospital, Zhejiang University School of Medicine, Hangzhou, Zhejiang, China. ${ }^{2}$ Department of Pathology, Sir Run Run Shaw Hospital, Zhejiang University School of Medicine, Hangzhou, Zhejiang, China. ${ }^{3}$ Image-Guided Bio-Molecular Intervention Research, Department of Radiology, University of Washington School of Medicine, Seattle, WA, USA.

Received: 4 May 2019 Accepted: 15 July 2019

Published online: 22 July 2019 


\section{References}

1. Rakic M, Patrlj L, Kopljar M, Klicek R, Kolovrat M, Loncar B, Busic Z. Gallbladder cancer. Hepatobiliary Surg Nutr. 2014;3(5):221-6.

2. Srivastava K, Srivastava A, Sharma KL, Mittal B. Candidate gene studies in gallbladder cancer: a systematic review and meta-analysis. Mutat Res. 2011;728(1-2):67-79.

3. Srivastava K, Srivastava A, Mittal B. Potential biomarkers in gallbladder cancer: present status and future directions. Biomarkers Biochem Indic Expo Response Susceptibility Chem. 2013;18(1):1-9.

4. Gabbi C, Kim HJ, Barros R, Korach-Andre M, Warner M, Gustafsson JA. Estrogen-dependent gallbladder carcinogenesis in LXRbeta-/- female mice. Proc Natl Acad Sci USA. 2010;107(33):14763-8.

5. Wistuba II, Gazdar AF. Gallbladder cancer: lessons from a rare tumour. Nat Rev Cancer. 2004;4(9):695-706.

6. Lazcano-Ponce EC, Miquel JF, Munoz N, Herrero R, Ferrecio C, Wistuba II, Alonso de Ruiz P, Aristi Urista G, Nervi F. Epidemiology and molecular pathology of gallbladder cancer. CA Cancer J Clin. 2001;51(6):349-64.

7. Hsing AW, Sakoda LC, Rashid A, Chen J, Shen MC, Han TQ, Wang BS, Gao YT. Body size and the risk of biliary tract cancer: a population-based study in China. Br J Cancer. 2008:99(5):811-5.

8. Zhu AX, Hong TS, Hezel AF, Kooby DA. Current management of gallbladder carcinoma. Oncologist. 2010;15(2):168-81.

9. Lee YS, Lee DG, Lee JY, Kim TR, Hong SS, Kwon SW, Kim YS. A formulated red ginseng extract upregulates CHOP and increases TRAIL-mediated cytotoxicity in human hepatocellular carcinoma cells. Int J Oncol. 2013;43(2):591-9.

10. Yamada N, Chung YS, Arimoto Y, Sawada T, Seki S, Sowa M. Establishment of a new human extrahepatic bile duct carcinoma cell line (OCUCh-LM1) and experimental liver metastatic model. Br J Cancer. 1995;71(3):543-8.

11. Ebinuma H, Imaeda H, Fukuda Y, Miyaguchi S, Yasui T, Hoshino T, Okamura T, Ariwa R, Saito H. A case of parathyroid hormone-related peptide producing gallbladder carcinoma and establishment of a cell line, PTHrPGBK. Digest Dis Sci. 2002;47(1):125-9.

12. Egami H, Sakamoto K, Yoshimura R, Kikuchi H, Akagi M. Establishment of a cell line of gallbladder carcinoma (GBK-1) producing human colony stimulating factor. Jpn J Cancer Res Gann. 1986;77(2):168-76.

13. Emura F, Kamma H, Ghosh M, Koike N, Kawamoto T, Saijo K, Ohno T, Ohkohchi N, Todoroki T. Establishment and characterization of novel xenograft models of human biliary tract carcinomas. Int J Oncol. 2003;23(5):1293-300.

14. He XW, Cao HQ, Xu LP, Zhou J, Xu L, Zhong ZX, Lu SC, Wu WX, Liu YB. Establishment and characterization of serial subpopulations with highly metastatic potential via different metastatic routes. Zhonghua yi xue za zhi. 2011;91(26):1852-5.

15. Homma S, Hasumura S, Nagamori S, Kameda H. Establishment and characterization of a human gall bladder carcinoma cell line NOZ. Hum Cell. 1988;1(1):95-7.

16. Jiao W, Miyazaki K, Kitajima Y. Exogenous expression of E-cadherin in gallbladder carcinoma cell line G-415 restores its cellular polarity and differentiation. Int J Oncol. 2001;19(6):1099-107.

17. Johzaki H, Iwasaki H, Nishida T, Isayama T, Kikuchi M. A human gallbladder adenocarcinoma cell line. Cancer. 1989;64(11):2262-8.

18. Koyama S, Yoshioka T, Mizushima A, Kawakita I, Yamagata S, Fukutomi H, Sakita T, Kondo I, Kikuchi M. Establishment of a cell line (G-415) from a human gallbladder carcinoma. Gan. 1980;71(4):574-5.

19. Ku JL, Yoon KA, Kim IJ, Kim WH, Jang JY, Suh KS, Kim SW, Park YH, Hwang $\mathrm{JH}$, Yoon $\mathrm{YB}$, et al. Establishment and characterisation of six human biliary tract cancer cell lines. Br J Cancer. 2002;87(2):187-93.

20. Li LF, Hu HZ, Liu C, Wang JH, Wu HP, Jin HJ, Su CQ, Jiang XQ, Liu J, Gu JZ, et al. Establishment and characterization of a human gallbladder carcinoma cell line EH-GB1 originated from a metastatic tumor. Zhonghua zhong liu za zhi Chin J Oncol. 2010;32(2):84-7.

21. Li XX, Wang J, Wang HL, Wang W, Yin XB, Li QW, Chen YY, Yi J. Characterization of cancer stem-like cells derived from a side population of a human gallbladder carcinoma cell line, SGC-996. Biochem Biophys Res Commun. 2012:419(4):728-34.

22. Liu YB, He XW, Wang JW, Li JT, Li KQ, Liu FB, Xue JF, Zhu JH, Li B, Peng SY. Establishment of liver metastasis model of human gallbladder cancer and isolation of the subpopulation with high metastatic potential. Zhonghua yi xue za zhi. 2006:86(30):2117-21
23. Maruiwa M. Establishment of a new human gallbladder carcinoma cell line (KMG-A) from an alpha-fetoprotein-producing gallbladder carcinoma transplanted into nude mice. Kurume Med J. 1987:34(3):133-46.

24. Morgan RT, Woods LK, Moore GE, McGavran L, Quinn LA, Semple TU. A human gallbladder adenocarcinoma cell line. In Vitro. 1981;17(6):503-10.

25. Nishida T, Iwasaki H, Johzaki H, Tanaka S, Watanabe R, Kikuchi M. A human gall-bladder signet ring cell carcinoma cell line. Pathol Int. 1997:47(6):368-76.

26. Wang JH, Li LF, Yu Y, Li B, Jin HJ, Shen DH, Li J, Jiang XQ, Qian QJ. Establishment and characterization of a cell line, EH-GB2, derived from hepatic metastasis of gallbladder cancer. Oncol Rep. 2012;27(3):775-82.

27. Liu ZY, Xu GL, Tao HH, Yang YQ, Fan YZ. Establishment and characterization of a novel highly aggressive gallbladder cancer cell line, TJ-GBC2. Cancer Cell Int. 2017;17:20.

28. Speirs V, Green AR, White MC. A comparative study of cytokine gene transcripts in normal and malignant breast tissue and primary cell cultures derived from the same tissue samples. Int J Cancer. 1996;66(4):551-6.

29. Kaur J, Ralhan R. Establishment and characterization of a cell line from smokeless tobacco associated oral squamous cell carcinoma. Oral Oncol. 2003:39(8):806-20.

30. Rohatgi N, Kaur J, Srivastava A, Ralhan R. Smokeless tobacco (khaini) extracts modulate gene expression in epithelial cell culture from an oral hyperplasia. Oral Oncol. 2005;41(8):806-20.

31. Rodriques SG, Stickels RR, Goeva A, Martin CA, Murray E, Vanderburg CR, Welch J, Chen LM, Chen F, Macosko EZ. Slide-seq: a scalable technology for measuring genome-wide expression at high spatial resolution. Science. 2019:363(6434):1463-7.

32. Wu CP, Zhou L, Gong HL, Du HD, Tian J, Sun S, Li JY. Establishment and characterization of a novel HPV-negative laryngeal squamous cell carcinoma cell line, FD-LSC-1, with missense and nonsense mutations of TP53 in the DNA-binding domain. Cancer Lett. 2014;342(1):92-103.

33. Twentyman PR, Luscombe M. A study of some variables in a tetrazolium dye (MTT) based assay for cell growth and chemosensitivity. $\mathrm{Br} J$ Cancer. 1987;56(3):279-85.

34. Seabright M. A rapid banding technique for human chromosomes. Lancet. 1971;2(7731):971-2.

35. Albini A, Iwamoto Y, Kleinman HK, Martin GR, Aaronson SA, Kozlowski JM, McEwan RN. A rapid in vitro assay for quantitating the invasive potential of tumor cells. Cancer Res. 1987;47(12):3239-45.

36. Kupferman ME, Jiffar T, El-Naggar A, Yilmaz T, Zhou G, Xie T, Feng L, Wang J, Holsinger FC, Yu D, et al. TrkB induces EMT and has a key role in invasion of head and neck squamous cell carcinoma. Oncogene. 2010;29(14):2047-59.

37. Sekine S, Shimada Y, Nagata T, Moriyama M, Omura T, Yoshioka I, Hori R, Matsui K, Sawada S, Okumura T, et al. Establishment and characterization of a new human gallbladder carcinoma cell line. Anticancer Res. 2012:32(8):3211-8.

38. Bell D, Roberts D, Karpowicz M, Hanna EY, Weber RS, El-Naggar AK. Clinical significance of Myb protein and downstream target genes in salivary adenoid cystic carcinoma. Cancer Biol Ther. 2011;12(7):569-73.

39. Uphoff CC, Drexler HG. Comparative antibiotic eradication of mycoplasma infections from continuous cell lines. Vitro Cell Dev Biol Anim. 2002;38(2):86-9.

40. Shukla SK, Singh G, Shahi KS, Bhuvan, Pant P. Staging, treatment, and future approaches of gallbladder carcinoma. J Gastrointest Cancer. 2018:49(1):9-15.

41. Buscemi S, Orlando E, Damiano G, Portelli F, Palumbo VD, Valentino A, Marrazzo A, Buscemi G, Lo Monte Al. "Pure" large cell neuroendocrine carcinoma of the gallbladder. Report of a case and review of the literature. Int J Surg. 2016;28(Suppl 1):S128-32

42. Pang $L$, Zhang $Y$, Wang $Y$, Kong J. Pathogenesis of gallbladder adenomyomatosis and its relationship with early-stage gallbladder carcinoma: an overview. Braz J Med Biol Res Revista brasileira de pesquisas medicas e biologicas. 2018;51(6):e7411.

43. Takiyama I, Terashima M, Ikeda K, Kawamura H, Kashiwaba M, Tamura G, Suto T, Nakashima F, Sasaki R, Saito K. Establishment and characterization of a new human extrahepatic bile duct carcinoma cell line (ICBD-1). Oncol Rep. 1998;5(2):463-7.

44. Yano H, Maruiwa M, lemura A, Mizoguchi A, Kojiro M. Establishment and characterization of a new human extrahepatic bile duct carcinoma cell line (KMBC). Cancer. 1992:69(7):1664-73. 
45. Chaudhary D, Ahluwalia R, Rai A. Synchronous breast cancer and gallbladder diseases-a chromosomal analysis: a pilot study at a tertiary care centre. Indian J Surg. 2017;79(6):544-8.

46. Jean A, Tardy F, Allatif O, Grosjean I, Blanquier B, Gerlier D. Assessing mycoplasma contamination of cell cultures by qPCR using a set of universal primer pairs targeting a $1.5 \mathrm{~kb}$ fragment of $16 \mathrm{~S}$ rRNA genes. PLoS ONE. 2017;12(2):e0172358

47. Liu B, Wang ZM, Wu XP, Liu CS, Li ZT, Liu J. Study of human gallbladder carcinoma cell line on its construction and biological behavior. J Surg Concept Pract. 2001;6(6):146-8.

48. Yang YQ, Tao HH, Yang HC. Establishment of primary gallbladder cell line SGC-996. J Tongji Univ. 2003;24(3):457-9.

49. Julich-Haertel H, Urban SK, Krawczyk M, Willms A, Jankowski K, Patkowski W, Kruk B, Krasnodebski M, Ligocka J, Schwab R, et al. Cancer-associated circulating large extracellular vesicles in cholangiocarcinoma and hepatocellular carcinoma. J Hepatol. 2017;67(2):282-92.
50. Mayr C, Ocker M, Ritter M, Pichler M, Neureiter D, Kiesslich T. Biliary tract cancer stem cells - translational options and challenges. World J Gastroenterol. 2017;23(14):2470-82.

51. Beyreis M, Gaisberger M, Jakab M, Neureiter D, Helm K, Ritter M, Kiesslich T, Mayr C. The cancer stem cell inhibitor napabucasin (BBI608) shows general cytotoxicity in biliary tract cancer cells and reduces cancer stem cell characteristics. Cancers. 2019;11(3):E276.

52. Kanthan R, Senger JL, Ahmed S, Kanthan SC. Gallbladder cancer in the 21st century. J Oncol. 2015;2015:967472.

\section{Publisher's Note}

Springer Nature remains neutral with regard to jurisdictional claims in published maps and institutional affiliations.
Ready to submit your research? Choose BMC and benefit from:

- fast, convenient online submission

- thorough peer review by experienced researchers in your field

- rapid publication on acceptance

- support for research data, including large and complex data types

- gold Open Access which fosters wider collaboration and increased citations

- maximum visibility for your research: over $100 \mathrm{M}$ website views per year

At BMC, research is always in progress.

Learn more biomedcentral.com/submissions 